\title{
Venous Malformation in the Neck
}

\author{
Bijan Kumar Adhikary, ${ }^{1}$ Sohag Kundu, ${ }^{1}$ Bhaskar Ghosh, ${ }^{1}$ Ramanuj Sinha ${ }^{1}$
}

$\underline{\text { Introduction }}$

\section{ABSTRACT}

Venous malformation is a benign vascular lesion. Approximately $40 \%$ of such cases occur in head and neck.

Case Report

Venous malformation in a 19 year old man is reported, which presented as a lateral neck swelling.

Discussion

The venous malformation in the head and neck region may confuse the surgeon in distinguishing it from its other common congeners e.g. hemangioma, lymphangioma etc. and may also cause dilemma regarding its treatment modality. Treatment options include surgery, laser therapy, sclerotherapy or a combination depending upon the complexity of the lesion.

$\underline{\text { Keywords }}$

Vascular Malformations; Angiography, Digital Subtraction; Jugular Veins

$\mathrm{V}$ enous malformation which comes under the broad heading of vascular malformation (Arterial, venous, lymphatic or combination) is an uncommon entity in the head neck region. They are present since birth but may manifest in later life with or without causing any symptoms.

\section{Case Report}

A 19 year old male patient presented to the ENT outpatient department with swelling on the leftside of neck for the one year along with mild pain and numbness around the swelling. (Fig. 1) The swelling was around 4 $\mathrm{cm} \times 3 \mathrm{~cm}$ in size, ovoid, occupying the lateral aspect of the middle third of the neck with ill-defined margin and apparently superficial to sternocleidomastoid muscle. It was soft, compressible, non-tender, not fixed to adjacent underlying or overlying structures and vertically mobile. There was neither any fluid thrill, pulsation, cystic fluctuation nor was there any change with Valsalva manoeuvre. There was no history of trauma or surgery. The temperature was not raised.

Examination of oral cavity, oropharynx and hypopharynx revealed no abnormality and no neck nodes or glands were palpable and there was no venous engorgement in the neck or around the lesion. Auscultation of the lesion did not produce any hum or bruit.
USG Doppler study revealed that it was a venous malformation, but feeding vessel could not be identified.

A lobulated vascular malformation was seen in digital subtraction angiography (Fig. 2). It was opacified on venous phase after injecting the dye in left internal carotid artery.(According to USG Doppler report there was a communication with intracranial venous sinus or upper part of left internal jugular vein.)

The patient was planned for surgical intervention as he was fit for anaesthesia and it was deemed feasible to remove the mass in its entirety surgically. A $5 \mathrm{~cm}$ vertical incision was made along the anterior border of the sternocleidomastoid muscle so as to reach the subplatysmal plane and to expose the sternocleidomastoid muscle.

The bluish lobulated mass was seen lying over the sternocleidomastoid muscle and was communicating with the external jugular vein. Exploration medially did not reveal any feeder vessel from common facial or internal jugular vein. Ligation of the communicating external jugular vein vessel was done under the muscle and lesion was excised. Wound was closed in two layers.
1 - Department of ENT, Medical College, Kolkata
Corresponding author:
Dr Bijan Kumar Adhikary
email: drbadhikary@gmail.com 


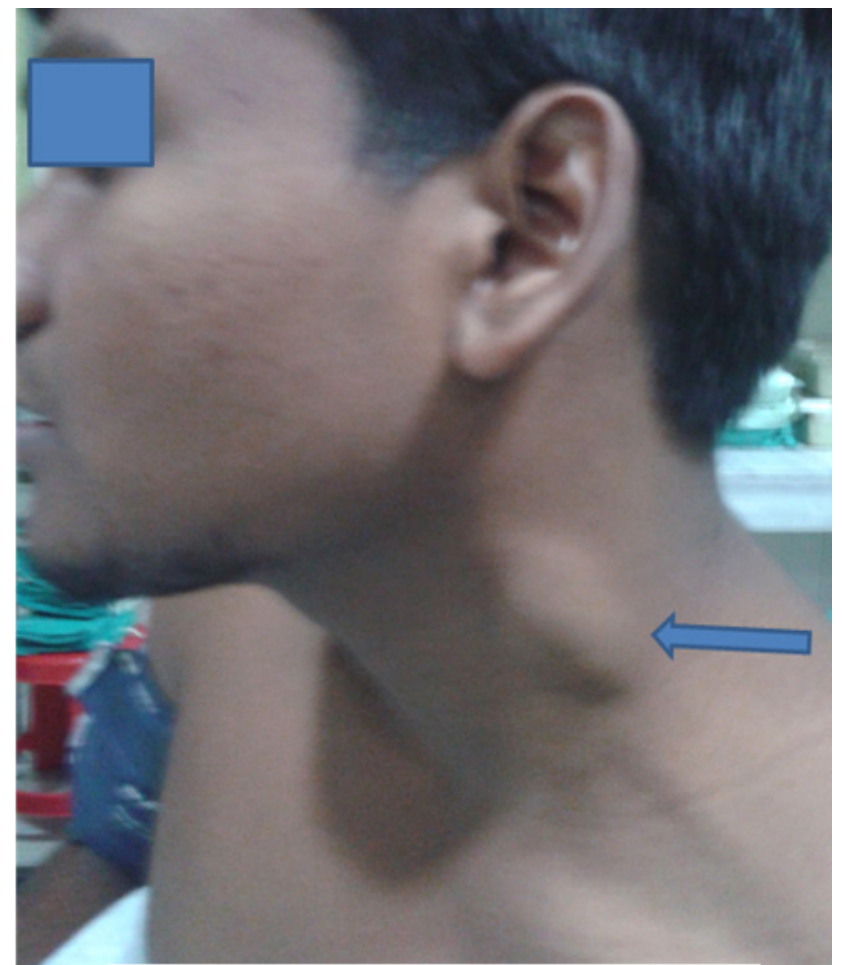

Fig.1 Clinical photograph at presentation. Arrow showing the venous swelling.

Biopsy revealed muscle fibres and fibroadipose tissue along with variable size of vascular channels lined by flattened epithelium consistent with venous malformation (Fig. 3).

\section{Discussion}

Approximately $40 \%$ of the venous malformations manifest in the head-neck region. ${ }^{1}$ Commonly affected sites are cheek, neck, palate and tongue.Its blood flow is low as it is a post capillary lesion. Majority of the cases are sporadic and commonly occur in the air passage,oral cavity and muscle. ${ }^{1}$ Venous malformation may be superficial or deep or it may be single or multiple. Venous malformation causes not only deformity but also other symptoms like pain, paraesthesia, ulcers,bleeding and compression or invasion of the surrounding structures. These may cause impairment of speech,swallowing,respiration or even lead to death due to bleeding or suffocation. ${ }^{2}$

Pathogenesis of venous malformation is unclear. It

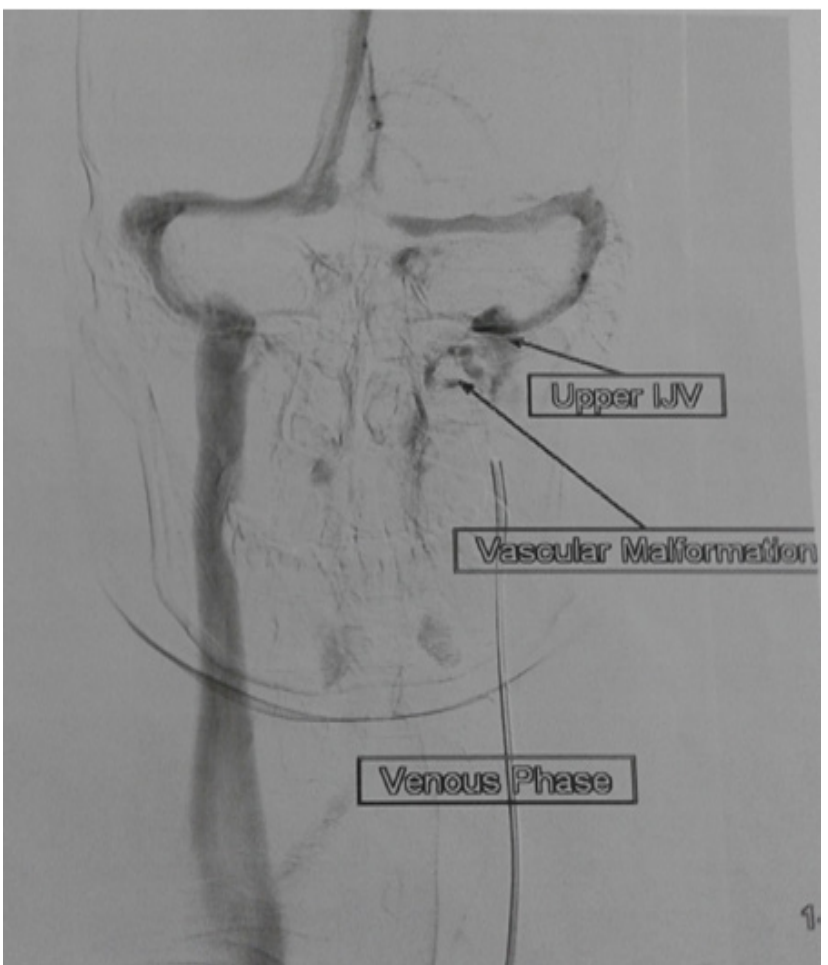

Fig.2. Digital subtraction angiogram

may be due to developmental defect of venous system. TIE2 receptor mutation has been seen in venous malformation syndrome(blue rubber bleb nevus syndrome) and multiple myocutaneous and venous malformation. ${ }^{3}$

Colour of the skin or mucous membrane may be blue or purple. In our case the lesion was typically lobulated, bluish red on gross morphology and its histopathology was characteristic of venous malformation.

Pain is a common symptom in venous malformation.A significant increase in nerve cells is seen in some venous malformations. ${ }^{4}$ Static venous pool leads to thrombosis and results in phlebitic syndrome. Expression of matrix metaloprotinase-9 was seen in intramuscular venous malformation. ${ }^{5}$ Progesteron receptors are highly expressed in some cases. ${ }^{5}$ In our case there was localized mild pain and numbness around the non tender swelling.

There are several methods of treatment of venous malformation including surgery,laser therapy,sclerotherapy,copper needles, electrocoagulation therapy. ${ }^{6-8}$ There are several advantages and 


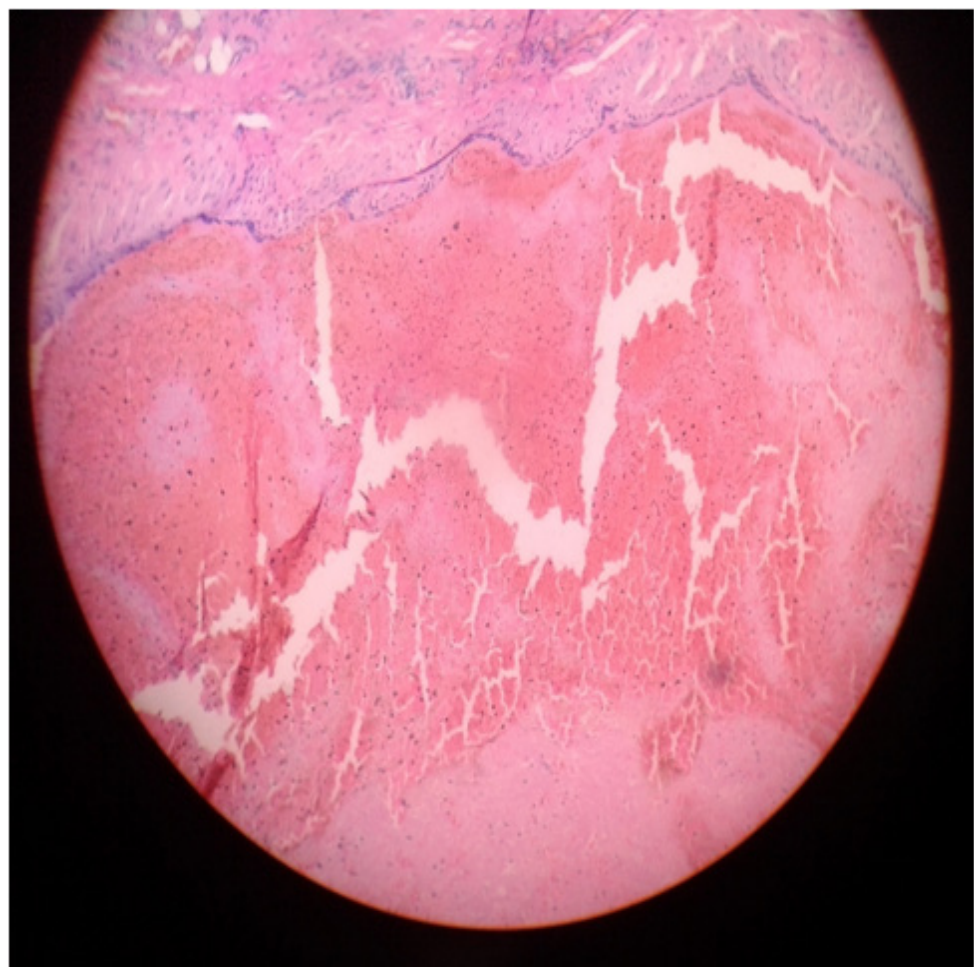

Fig.3. Histopathological features (H\&E, 10X)

disadvantages in each method. Treatment depends on site,size and others factors. In large venous malformations multimodality treatment is required.In our case as the lesion was of $4 \mathrm{~cm} \times 3 \mathrm{~cm}$ in diameter and there was a distinct feeder on DSA we opted for the monomodality curative surgery where proper exposure of the lesion and ligation of the feeder suffices.

\section{References}

1. Buckmiller LM, Richter GT, Suen JY. Diagnosis and management of hemangiomas and vascular malformations of the head and neck. Oral Dis. 2010; 16:405-18

2. Dubois J, Garel L. Imaging and therapeutic approach of hemangiomas and vascular malformations in the pediatric age group. Pediatr Radiol. 1999; 29:879-93

3. Boon LM, Mulliken JB, Enjolras O, Vikkula M. Glomuvenous malformation (glomangioma) and venous malformation: distinct clinicopathologic and genetic entities. Arch Dermatol.

\section{$2004 ; 140: 971-6$}

4. Meijer-Jorna LB, Breugem CC, de Boer OJ, Ploegmakers JP, van der Horst CM, van der Wal AC. Presence of a distinct neural component in congenital vascular malformations relates to the histological type and location of the lesion. Hum Pathol. 2009; 40:1467-73

5. Duyka LJ, Fan CY, Coviello-Malle JM, Buckmiller L, Suen JY. Progesterone receptors identified in vascular malformations of the head and neck. Otolaryngol Head Neck Surg. 2009; 141:491-5

6. Lewin JS, Merkle EM, Duerk JL, Tarr RW. Low-flow vascular malformations in the head and neck: safety and feasibility of MR imaging-guided percutaneous sclerotherapy--preliminary experience with 14 procedures in three patients. Radiology 1999; 211:566-70

7. Ogawa Y, Inoue K. Electrothrombosis as a treatment angioma in the face and scalp and varicosis of the leg. Plast Reconstr Surg. 1982; 70:310-8

8. Li ZP. Therapeutic coagulation induced in cavernous hemangioma by use of percutaneous copper needles. Plast Reconstr Surg. 1992; 89: 613-22. 